\title{
Minimum Two-year Results of Revision Total Knee Arthroplasty Following Infectious or Non-infectious Causes
}

\author{
Kyoung-Jai Lee, MD, Jae-Young Moon, MD, Eun-Kyoo Song, MD, Hong-An Lim, MD and Jong-Keun Seon, \\ $\mathrm{MD}$
}

Center for Joint Disease, Chonnam National University Hwasun Hospital, Chonnam National University Medical School, Hwasun, Korea

\begin{abstract}
Purpose: To compare clinical outcome of revision total knee arthroplasty (TKA) between the infected and non-infected groups.
Materials and Methods: This study compared the clinical and radiographic results of 21 infected and 15 non-infected revision TKAs at a minimum 2- years follow-up. Clinical evaluations were assessed using the range of motion (ROM), Hospital for Special Surgery (HSS) score, Knee Society Knee Score (KSKS), Knee Society Function Score (KSFS), and Western Ontario and McMaster Universities (WOMAC) score. Radiologic evaluations were assessed using the radiographic results of the American Knee Society and joint line change.

Results: Patients operated for non-infectious causes had significantly better postoperative ROM than the infected group (infected group, $101.7^{\circ}$; noninfected group, $117.8^{\circ}$ ). The infected group achieved significantly poor HSS (79.2 vs. 85.5), KSKS (75.5 vs. 86.6), KSFS (76.9 vs. 85.5), WOMAC (30.3 vs. 21.2) scores than the non-infected group. Postoperative joint line elevation was lower in the infected versus non-infected group (0.5 mm vs. 2.1 $\mathrm{mm})$, but there was no significant difference.

Conclusions: Revision TKA is an effective treatment that can provide successful results in the infected as well as non-infected patients. The overall results of non-infected revision were more satisfactory than infected revision.
\end{abstract}

Key words: Infection, Non-infection, Revision total knee arthroplasty.

\section{Introduction}

Total knee arthroplasty (TKA) has been performed with increasing frequency with the advent of aging society and economic development. TKA provides successful outcome in $\geq 90 \%$ of patients due to the improvement in implant design and

Received May 2, 2011; Revised (1st) August 23, 2011;

(2nd) March 31, 2012; (3rd) July 7, 2012; (4th) July 9, 2012;

(5th) August 22, 2012; Accepted September 3, 2012.

Correspondence to: Jong-Keun Seon, MD.

Center for Joint Disease, Chonnam National University Hwasun

Hospital, Chonnam National University Medical School, 322 Seoyang-

ro, Hwasun 519-809, Korea.

Tel: +82-61-379-7676, Fax: +82-61-379-7681

Email: seonbell@yahoo.co.kr

This is an Open Access article distributed under the terms of the Creative Commons Attribution Non-Commercial License (http://creativecommons.org/licenses/by-nc/3.0/) which permits unrestricted non-commercial use, distribution, and reproduction in any medium, provided the original work is properly cited. surgical techniques ${ }^{1,2)}$. However, the increase in the employment of the procedure has led to a greater need for revision $\mathrm{TKA}^{3)}$. Advanced implant design and surgical techniques have also enabled revision TKA to yield more promising results. Still, revision TKA is less satisfactory than primary TKA in many cases with reported success rates of 30-89\%. In addition, revision procedures are technically more demanding because of the bone loss during implant removal, instability, skin and soft tissue vulnerability, and infection ${ }^{2,4-6)}$.

The causes of revision TKA can be largely divided into infectious and non-infectious. Non-infectious causes are often related to component loosening, wear, instability, malalignment, and periprosthetic fractures. The results of revision TKA for noninfectious reasons were less satisfactory than those of primary TKA in some studies ${ }^{4,7)}$, whereas comparable to the primary surgery according to the study by Insall and Dethmers ${ }^{8)}$.

The incidence of deep infection following TKA has been decreasing due to the development of prophylactic antibiotics and thorough infection control, but infection is still known as one of the most common causes of revision ${ }^{9}$. Among various 
treatment options for infection after TKA including continuous antibiotic infusion, debridement, revision TKA, and arthrodesis, two-stage reimplantation has been considered as the gold standard ${ }^{10,11}$. There are numerous studies showing the results of revision TKA for infection are less satisfactory than those for non-infectious causes. This was attributed to limited joint movement after surgery and unstable implant fixation due to severe bone defect and soft tissue damage ${ }^{1,4,11-13)}$. On the other hand, Bose et al. ${ }^{14)}$ reported there was no significant difference in the clinical results of revision TKA between the infected and non-infected groups, and Park et al. ${ }^{15}$ obtained successful results of two-stage reimplantation using mobile antibiotic-impregnated cement spacers in TKA patients with infection. In the study by Patil et al. ${ }^{16}$, the clinical results of septic revision TKA were superior to those of aseptic revision TKA.

There are few comparison studies on infected and non-infected revision TKA because of the small number of revision TKA cases compared to primary TKA and accompanying bone deficiency and other complications. The purpose of this study was to compare the clinical and radiographic results of revision TKA using a mobile-bearing cemented prosthesis between the infected group and non-infected group.

\section{Materials and Methods}

Of the 46 patients who underwent revision TKA at our institution between February 2004 and February 2009, 36 patients who were available for $\geq 2$ years of follow-up were included in this study. When the total revision TKA patients were divided into the infected group and non-infected group, the number of patients who were followed up for $\geq 2$ years were 21 out of 26 in the infected group (follow-up rate, 80.8\%) and 15 out of 20 in the non-infected group (follow-up rate, 75.0\%). Their mean age at the time of revision surgery was 68.3 years (range, 48-90 years) in the infected group and 66.0 years (range, 56-75 years) in the non-infected group. There were 7 males ( 3 in the infected group and 4 in the non-infected group) and 29 females (18 in the infected group and 11 in the non-infected group). In the infected group, 4 patients had primary TKA at our institution and were diagnosed with infection during the postoperative follow-up, whereas 17 patients were transferred from other hospitals. The mean interval from primary TKA to the first-stage procedure and from the first-stage procedure one-stage to the second-stage reimplantation was 20.3 months (range, 2.7-108.7 months) and 7.3 months (range, 3.0-16.8 months), respectively, in the infected group. The mean interval from primary TKA to revision was
221.5 months (range, 3.9-1329.5 months) in the non-infected group. The mean follow-up period was 35.7 months (range, 24.236.3 months) in the infected group and 50.5 months (range, 27.495.9 months) in the non-infected group (Table 1). There was no statistically significant intergroup difference in the age and the mean follow-up period ( $\mathrm{p}>0.05)$.

Infection was diagnosed if any of the following criteria were satisfied: 1) presence of systemic symptoms of infection such as pain and swelling of the knee and a joint fluid white blood cell count of $(\mathrm{WBC}) \geq 20,000-30,000 / \mu \mathrm{L}$ with polymorphonuclear leukocytes $\geq 90 \%$ or a positive joint fluid culture; 2 ) a positive bacterial culture from a specimen obtained during the first-stage procedure or $\geq 5$ polymorphonuclear neutrophils per high-power field; 3) a WBC of $\geq 15,000$ cells $/ \mathrm{mm}^{3}$ with hypersegmented neutrophils $\geq 90 \%$; 4 ) an erythrocyte sedimentation rate (ESR) of $\geq 70-80 \mathrm{~mm} / \mathrm{hr}$ or a C-reactive protein (CRP) level of 10.0 $\mathrm{mg} / \mathrm{dL}$; and 5) presence of draining fistulas ${ }^{17)}$. In the infected group, two-stage reimplantation was performed using mobile antibiotic-impregnated cement spacers (Fig. 1). Once an

Table 1. Demographic Data of Revision Total Knee Arthroplasty

\begin{tabular}{|c|c|c|}
\hline & $\begin{array}{l}\text { Infected group } \\
\qquad(\mathrm{n}=21)\end{array}$ & $\begin{array}{l}\text { Non-infected } \\
\text { group }(n=15)\end{array}$ \\
\hline Age (yr) & $\begin{array}{c}68.3 \\
\text { (range, } 48-90 \text { ) }\end{array}$ & $\begin{array}{c}66.0 \\
\text { (range, 56-75) }\end{array}$ \\
\hline Gender (M:F) & $3: 18$ & $4: 11$ \\
\hline Follow-up (mo) & $\begin{array}{c}40.2 \\
\text { (range, } 24.2-63.3 \text { ) }\end{array}$ & $\begin{array}{c}42.8 \\
\text { (range, 27.4-62.6) }\end{array}$ \\
\hline \multicolumn{3}{|l|}{ Operative technique } \\
\hline Rectus snip & 11 & 15 \\
\hline Tibial tubercle osteotomy & 8 & 0 \\
\hline V-Y Quadricepsplasty & 0 & 0 \\
\hline \multicolumn{3}{|l|}{ Implant } \\
\hline LCCK system & 12 & 8 \\
\hline Scorpio system & 9 & 1 \\
\hline PFC Sigma knee system & 0 & 2 \\
\hline Rotating Hinge system & 0 & 1 \\
\hline NexGen system & 0 & 3 \\
\hline \multicolumn{3}{|l|}{ Stem } \\
\hline Femoral & 21 & 7 \\
\hline Tibial & 21 & 7 \\
\hline \multicolumn{3}{|l|}{ Metal augment } \\
\hline Femoral & 20 & 5 \\
\hline Tibial & 14 & 3 \\
\hline Strut bone allograft & 1 & 2 \\
\hline
\end{tabular}




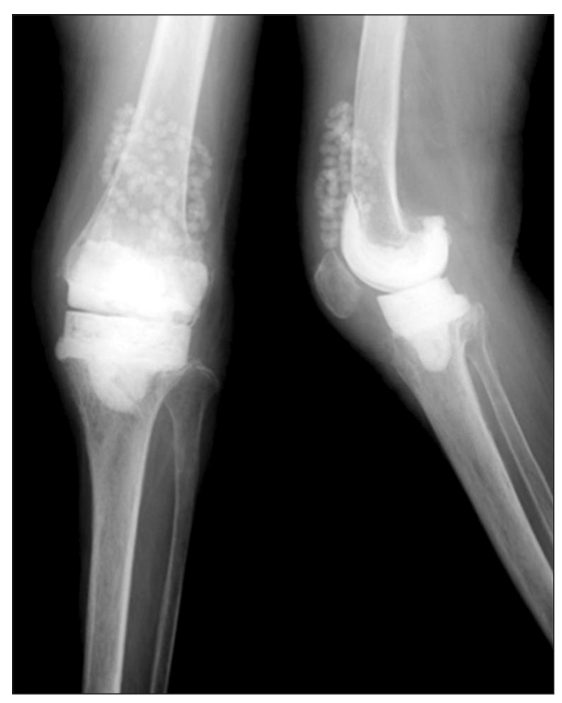

Fig. 1. Radiographs showing mobile cement spacer.

infection is diagnosed, debridement and lavage were thoroughly performed. The type of antibiotics used for the cement spacer in the first-stage procedure was determined as those sensitive to cultured organisms. In the cases with negative culture results, $2 \mathrm{~g}$ of vancomycin and $2.25 \mathrm{~g}$ of tazocin were mixed with 40 $\mathrm{g}$ bone cement containing $1 \mathrm{~g}$ erythromycin. The spacer was created using each package of bone cement for the tibial area and femoral area. In cases with suspected fungal infection, 50 $\mathrm{mg}$ of amphotericin was added to the mixture. In the adjacent soft tissues, $60-90$ beads that are $5 \mathrm{~mm}$ in diameter and made of the same proportion of antibiotics to cement were implanted. If the preoperative culture was positive, sensitive antibiotics were intravenously injected and if negative, $1 \mathrm{~g}$ of cetrazole was administered. The type of antibiotics was changed according to the intraoperative culture results and the intravenous administration was continued for 6 weeks. The second-stage reimplantation was planned if systemic symptoms accompanying knee pain, suppuration, open wounds, and fistulas disappeared and blood parameters such as WBC, ESR, and CRP were normal in more than two consecutive assessments performed with an interval of 1 month. The final revision procedure was performed if $\leq 5$ polymorphonuclear leukocytes were observed on the intraoperative frozen section biopsy of specimens from $\geq 3$ areas with a magnification of $\times 400$ and there was no sign of infection observable with the naked eye. In cases with 5-10 polymorphonuclear leukocytes, revision was determined if infection was considered resolved based on the assessment of clinical symptoms, postoperative condition, blood test results, and intraoperative naked-eye inspection.
In the non-infected group, the causes of revision were component loosening in 4, polyethylene wear and breakdown in 4 , instability in 2 , periprosthetic fracture in 3 , and polyethylene dislocation in 2 patients, on all of which one-stage revision was performed. In 2 patients, periprosthetic fracture was accompanied by component loosening.

In the revision TKA, rectus snip was performed in 11 patients in the infected group and 15 patients in the non-infected group, whereas tibial tubercle osteotomy was done in 8 patients in the infected group and in none of the non-infected group. V-Y Quadricepsplasty was not used in both groups. The LCCK system (Zimmer, Warsaw, IN, USA) and Scorpio system (Stryker Howmedica Osteonics, Mahway, NJ, USA) were used in 12 and 9 patients, respectively, in the infected group $(n=21)$ and in 8 patients and 1 patient, respectively, in the non-infected group $(n=15)$. In the remaining patients of the non-infected group, revision surgery was performed using the PFC Sigma knee system (Johnson \& Johnson, Warsaw, IN, USA) in 2 patients, the rotating Hinge system (Stryker Howmedica Osteonics) in 1 patient with severe instability, and the NexGen system (Zimmer) and stems in 3 patients with relatively little bone loss. Both the femoral and tibial stems were used in all of the patients in the infected group and in 5 patients in the non-infected group. In the remaining patients of the non-infected group, a femoral stem was used in 2 patients and a tibial stem in 2 patients. Metal augmentation for bone defect was used in 20 patients for the femur and 14 patients for the tibia in the infected group and in 5 patients for the femur and 3 patients for the tibia in the non-infected group. Structural bone graft reconstruction was performed in 1 patient in the infected group and in 2 patients with severe periprosthetic fracture in the non-infected group (Table 1).

The postoperative rehabilitation protocol was the same in both groups. Continuous passive motion was initiated from the 1st postoperative day. Active motion exercises and quadriceps femoris strengthening exercises were started from the 2nd postoperative day. Once normal quadriceps femoris strength was achieved, partial weight bearing with crutch assistance was initiated. Weigh bearing was not permitted until radiographic evidence of union was achieved in patients with tibial tubercle osteotomy or struactural bone allograft reconstruction. The patients were educated to continue with the rehabilitation program after hospital discharge and asked for regular follow-up at 3,6,9,12 months after surgery and once a year thereafter.

Clinical and radiographic assessments were performed in all the patients preoperatively and at the last follow-up. The clinical 
assessment was based on the range of motion (ROM), Hospital for Special Surgery (HSS) score, Knee Society score (KSS), and Western Ontario and McMaster Universities (WOMAC) score. The ROM was measured using a goniometer by the same surgeon. In the infected group, the ROM measured before the first-stage procedure was used as the preoperative ROM. On the radiographic assessment, the Knee Society roentgenographic evaluation system was used to assess the femorotibial angle, radiolucency around the femur and tibia on the anteroposterior and lateral radiographs ${ }^{18}$. Changes in the joint line height were also included in the assessment. The joint line height in the unoperated contralateral knee was compared with the postoperative height in the operated knee. If the contralateral knee had been operated, the measurement obtained before primary TKA was used for the assessment. The joint line height was measured as the perpendicular distance between a line connecting the most distal points of the medial and lateral femoral condyles and a parallel line extending to the fibular head on the anteroposterior radiographs. The distance between the medial and lateral condyles of the femur was measured on the contralateral knee and the operated knee to avoid errors caused by radiographic image magnification (Fig. 2). Statistical analysis was done using the SPSS ver. 14.0 software (SPSS Inc., Chicago, IL, USA). According to the normality test, intergroup comparisons were made using the parametric Student's t-test and
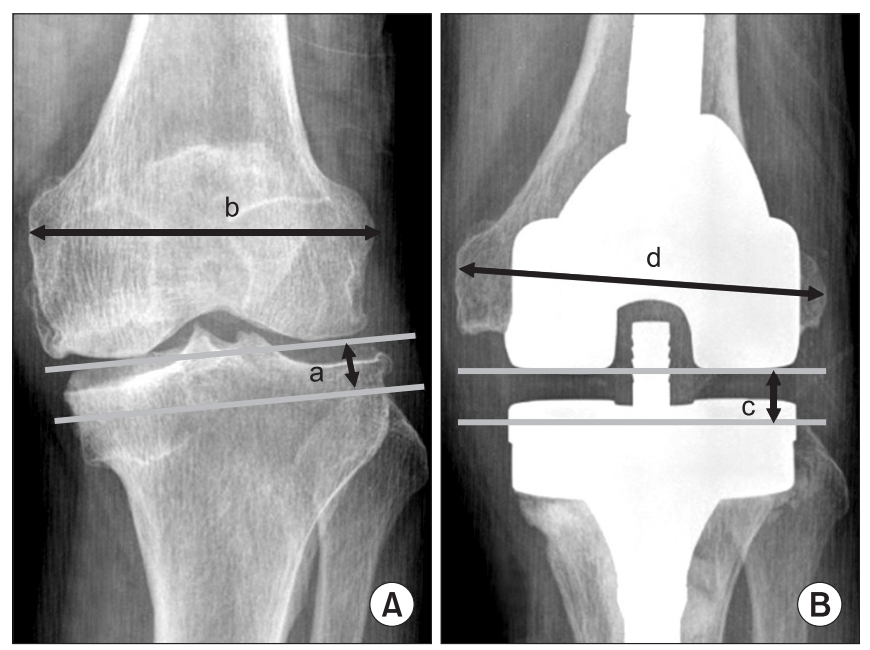

Fig. 2. Measurement of the joint line position change on the AP radiograph. (A) a: preoperative joint line height, b: preoperative distance between the medial and lateral femoral epicondyles, (B) c: postoperative joint line height, $d$ : postoperative distance between the medial and lateral femoral epicondyles. The difference (D) between preoperative and postoperative joint line was calculated as: $\mathrm{D}=(\mathrm{b} / \mathrm{d}) \mathrm{c}-\mathrm{a}$. the nonparametric Mann-Whitney test.

\section{Results}

\section{Clinical Results}

The mean ROM was improved in both groups from $65.2^{\circ}$ (range, $0^{\circ}-125^{\circ}$ ) preoperatively to $101.7^{\circ}$ (range, $90^{\circ}-130^{\circ}$ ) postoperatively in the infected group and from $99.9^{\circ}$ (range, $0^{\circ}-140^{\circ}$ ) preoperatively to $117.8^{\circ}$ (range, $85^{\circ}-140^{\circ}$ ) postoperatively in the non-infected group. The increase in the ROM was significantly high in the infected group compared to the non-infected group. The pre- and postoperative ROM values were significantly greater in the non-infected group ( $\mathrm{p}=0.004, \mathrm{p}=0.008$ ) (Table 2).

The HSS score was significantly improved postoperatively in both groups $(\mathrm{p}<0.001)$. There was no statistically significant intergroup difference in the mean preoperative HSS score, but the mean postoperative HSS score was remarkably greater in the non-infected group ( $\mathrm{p}=0.039)$ (Table 2).

The mean Knee Society Knee Score (KSKS) and Knee Society

Table 2. Clinical and Radiologic Outcome of the Infected and Noninfected Revision Total Knee Arthroplasty

\begin{tabular}{lccc}
\hline & $\begin{array}{c}\text { Infected } \\
\text { group }\end{array}$ & $\begin{array}{c}\text { Non-infected } \\
\text { group }\end{array}$ & p-value \\
\hline $\begin{array}{l}\text { Preoperative } \\
\text { ROM }\end{array}$ & & & \\
Extension $\left({ }^{\circ}\right)$ & $8.8 \pm 8.9$ & $4.8 \pm 6.6$ & 0.135 \\
Further Flexion $\left(^{\circ}\right)$ & $74.0 \pm 37.6$ & $104.7 \pm 34.8$ & 0.004 \\
Mean ROM $\left(^{\circ}\right)$ & $65.2 \pm 42.0$ & $99.9 \pm 38.0$ & 0.004 \\
HSS score & $47.4 \pm 14.2$ & $56.5 \pm 18.4$ & 0.238 \\
KSKS & $44.1 \pm 17.9$ & $44.6 \pm 14.9$ & 0.885 \\
KSFS & $28.1 \pm 16.2$ & $33.7 \pm 21.1$ & 0.619 \\
WOMAC & $60.8 \pm 13.5$ & $60.9 \pm 14.1$ & 0.468 \\
FT angle $\left({ }^{\circ}\right)$ & $4.1 \pm 5.8$ & $4.7 \pm 4.4$ & 0.312 \\
Postoperative & & & \\
Extension $\left({ }^{\circ}\right)$ & $2.5 \pm 2.3$ & $1.2 \pm 0.9$ & 0.348 \\
Further flexion $\left({ }^{\circ}\right)$ & $104.2 \pm 14.4$ & $119.0 \pm 20.7$ & 0.008 \\
Mean ROM $\left({ }^{\circ}\right)$ & $101.7 \pm 17.2$ & $117.8 \pm 20.9$ & 0.008 \\
HSS score & $79.2 \pm 9.8$ & $85.5 \pm 10.2$ & 0.039 \\
KSKS & $75.5 \pm 11.9$ & $86.6 \pm 9.6$ & 0.017 \\
KSFS & $76.9 \pm 12.0$ & $85.5 \pm 10.6$ & 0.016 \\
WOMAC & $30.3 \pm 13.9$ & $21.2 \pm 11.5$ & 0.005 \\
FT angle $\left({ }^{\circ}\right)$ & $-3.8 \pm 3.5$ & $-5.7 \pm 3.6$ & 0.506 \\
\hline
\end{tabular}

ROM: range of motion, HSS: Hospital for Special Surgery, KSKS: Knee Society Knee Score, KSFS: Knee Society Function Score, FT angle: femoro-tibial angle (varus: +, valgus: -). 

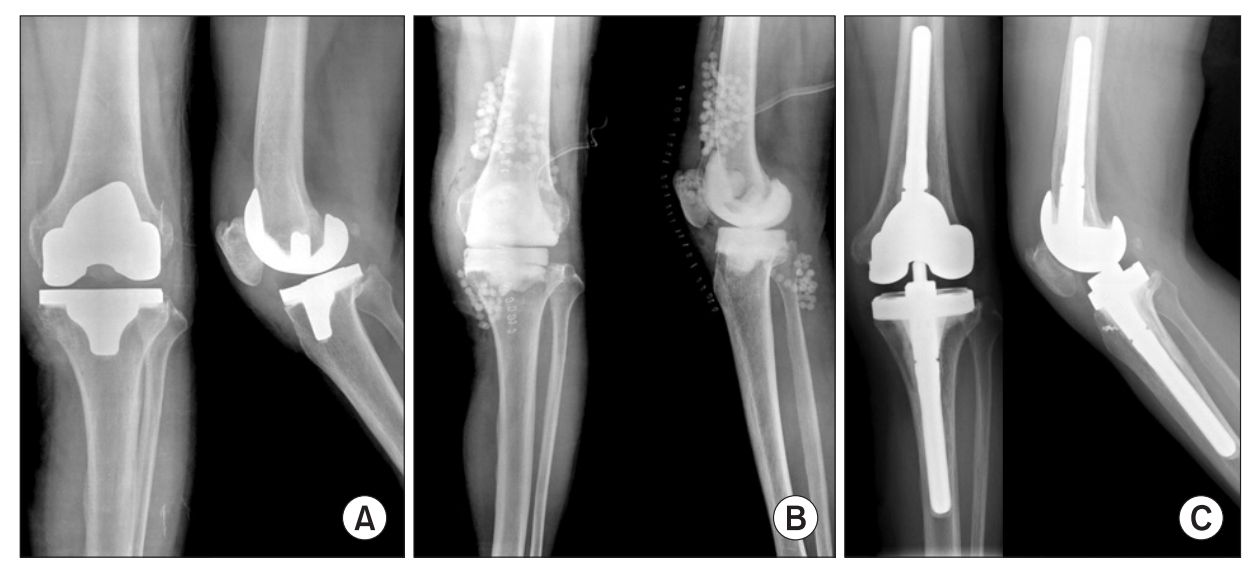

Fig. 3. (A) A 74-year-old woman visited our clinic with an infection of the left following total knee arthroplasty that had been done in another hospital 13 months ago. (B) We performed the first stage reimplantation with an articulating cement spacer and beads. (C) The radiograph at 3 years after the revision shows satisfactory results.
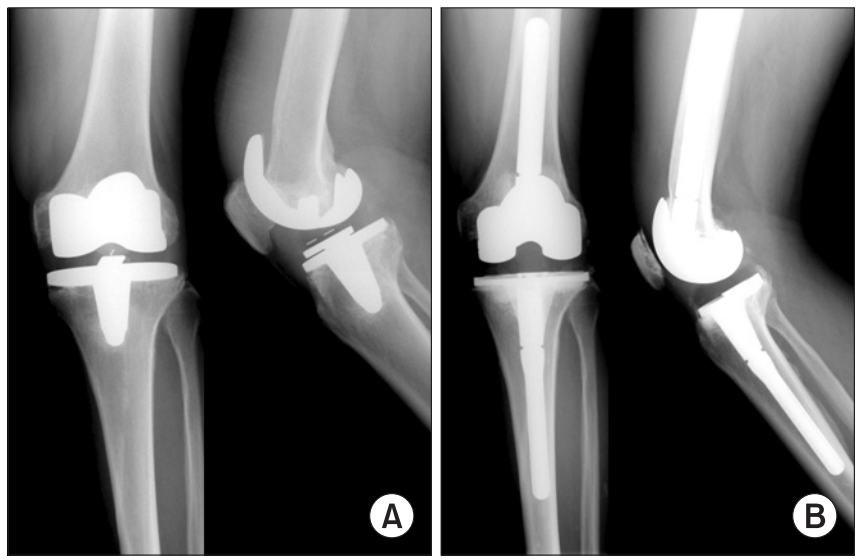

Fig. 4. (A) A 60-year-old man visited our clinic for left knee pain and the radiograph shows femoral component aseptic loosening. (B) The radiograph at 2 years after the revision shows satisfactory results.

Function Score (KSFS) were improved postoperatively in both groups $(\mathrm{p}<0.001)$. There was no notable intergroup difference in the mean preoperative KSKS and KSFS, but the mean postoperative values were significantly greater in the non-infected group ( $\mathrm{p}=0.017, \mathrm{p}=016)$ (Table 2).

The mean WOMAC score was 60.8 preoperatively and 30.3 postoperatively in the infected group and 60.9 preoperatively and 21.2 postoperatively in the non-infected group. The mean preoperative WOMAC score was not significantly different between the groups ( $\mathrm{p}=0.468$ ), but the mean postoperative value was notably higher in the non-infected group $(\mathrm{p}=0.005)$ (Table 2).

\section{Radiographic Results}

The mean femorotibial angle was corrected from $4.1^{\circ}$ varus preoperatively to $3.8^{\circ}$ valgus postoperatively in the infected group and from $4.7^{\circ}$ varus preoperatively to $5.7^{\circ}$ valgus postoperatively in the non-infected group and there was no significant different between the groups in the pre-and postoperative values $(\mathrm{p}=0.468$,
Table 3. Difference in the Average Joint Line Elevation between the Two Groups

\begin{tabular}{lcccc}
\hline Difference (D, mm) & Mean & Range & $\begin{array}{c}\text { Standard } \\
\text { deviation }\end{array}$ & $\begin{array}{c}\text { Outlier } \\
(> \pm 8 \mathrm{~mm})\end{array}$ \\
\hline Infective group & 0.5 & $-8.7-9.5$ & 4.6 & 2 cases \\
Non-infective group & 2.1 & $-6.9-17.0$ & 5.2 & 1 cases \\
\hline
\end{tabular}

p-value $=0.236$.

$\mathrm{p}=0.056$ ) (Table 2). A radiolucent zone of $\geq 2 \mathrm{~mm}$ was not observed in all patients during the follow-up, whereas $<2 \mathrm{~mm}$ radiolucent lines were observed in 3 patients ( 2 in the infected group and 1 in the non-infected group). All the radiolucent lines did not progress during the follow-up period (Figs. 3, 4). The mean increase in the joint line height was $0.5 \mathrm{~mm}$ in the infected group and $2.1 \mathrm{~mm}$ in the non-infected group. More than $8 \mathrm{~mm}$ change in the joint line height was observed in 2 patients in the infected group and in 1 patient in the non-infected group (Table $3)$.

\section{Complications}

Deep infection occurred in 3 patients in the infected group and in 1 patient in the non-infected group. The patients had no reinfection at one year after two-stage reimplantation and obtained good ROM $\left(5^{\circ}-100^{\circ}\right)$. During the postoperative rehabilitation period, a patellar tendon rupture in and a periprosthetic fracture were observed in 1 patient each in the non-infected group. The ruptured patellar tendon was treated with patellar tendon suture and quadriceps femoris turndown technique and the fracture with fixation using a metal plate.

\section{Discussion}

On the clinical outcome of revision TKA, Insall ${ }^{10)}$ reported 
that good or excellent results were obtained in $89 \%$ of patients, whereas satisfying results were achieved in $46 \%$ in the study by Goldberg et al. ${ }^{4)}$ and in only $30 \%$ in the study by Cameron et al. ${ }^{2}$. Direct comparison of these studies is difficult due to the differences in the follow-up period and criteria of success and failure. However, the general consensus is that the results of revision TKA is less satisfactory than those of primary TKA due to a variety of factors including the soft tissue weakness, bone deficiency, limited ROM before revision.

Many studies have shown that the results of revision TKA including the postoperative ROM are inferior in patients with infection than those without infection ${ }^{1,411-13)}$. This can be attributed to restriction on the ROM, preoperative joint function impairment, and soft tissue fibrosis due to repeated operations in patients with an infection ${ }^{8,11}$. However, some recent studies have suggested that revision TKA for infection can be as successful as that for non-infectious causes with use of mobile antibiotic impregnated cement spacers to compensate for bone loss and soft tissue fibrosis ${ }^{19,20)}$. On the other hand, Wang et al. ${ }^{21)}$ reported that the non-infected group obtained higher knee score and greater ROM than the infected group, whereas the function score and patient satisfaction were identical in both groups. And, Patil et al. ${ }^{16)}$ reported that the SF-36 score, a quality of life index, and knee score were higher in the infected group than noninfected group. Likewise, there is diverse comparative reports on results of the infected and non-infected groups. In the current study, the clinical results based on the HSS score, KSKS, KSFS, and WOMAC score were more satisfying in the non-infected group at statistically significant levels $(\mathrm{p}<0.05)$. The pre- and postoperative ROM were significantly greater in the non-infected group $(\mathrm{p}<0.05)$. We attributed these results to the fact that the ROM before the primary procedure was smaller in the infected group, repeated operations resulted in more soft tissue and skin damage, and the ROM was limited due to the use of antibiotic impregnated cement spacers in the two-stage reimplantation.

However, the clinical and radiographic results were within the satisfactory range in the infected group as well. Recurrence of an infection could be prevented with proper curettage. Joint mobility could be maintained during infection healing with the use of mobile antibiotic impregnated cement spacers for prevention of soft tissue adhesion. Balanced flexion-extension gap was achieved and joint line height was restored by using the stemmed prosthesis and metal augmentation to compensate for bone loss. On the clinical results, the mean postoperative ROM $\left(104.2^{\circ}\right.$; range, $\left.90^{\circ}-130^{\circ}\right)$ in the infected group was satisfactory. Considering that $\geq 120^{\circ}$ of high flexion is necessary for kneeling and sitting cross-legged on the floor in Korean culture, therefore, the relatively low clinical results in the infected group compared to those in the non-infected group can be attributed to the limitations in daily living activities.

The non-infectious causes of revision TKA include implant loosening and wear, instability, and malalignment. Bargren et al. ${ }^{22)}$ reported that malalignment is present in most of the TKA patients. In the current study, the degree of malalignment was greater in the infected group: the mean preoperative femorotibial angle was $4.1^{\circ}$ varus in the infected group, whereas $4.7^{\circ}$ varus in the non-infected group.

Bone deficiency is one of the most important factors that influence the success of TKA ${ }^{23}$. Metal augmentation can be effective in preventing changes in the joint line height, but may cause corrosion in the long-term and accordingly poor overall long-term outcome $e^{24,25)}$. In this study, the infected group had more extensive bone deficiency than the non-infected group. Thus, we used more metal augmentation materials in the infected group during revision surgery, which improved the clinical outcome during the short-term follow-up period. In spite of this, we believe the results should be confirmed by a long-term followup.

There is controversy regarding the radiolucency after TKA or revision TKA. Some authors associate radiolucent lines with the lack of firm stabilization between the tibia and bone cement ${ }^{26,27)}$. On the other hand, Reckling et al. ${ }^{28)}$ reported that the presence of progressive radiolucent lines do not signify looseness of the implant. In this study, $\geq 2 \mathrm{~mm}$ radiolucency was not observed in the tibia and femur in all the patients and the $<2 \mathrm{~mm}$ radiolucent lines in 3 patients did not progress or result in loosening of the prosthesis.

Restoration of the joint line height is crucial to the success of TKA. Figgie et al. ${ }^{29)}$ reported that joint line height was significantly correlated with the functional knee score, ROM, patellofemoral pain, and mechanical symptoms, and $\geq 8 \mathrm{~mm}$ change in the joint line height increased the need for revision. Ryu et al. ${ }^{30)}$ reported that the ROM was good in patients with $2.1 \mathrm{~mm}$ change in the joint line height, whereas the ROM was poor in patients with approximately 3 times greater changes (5.7 $\mathrm{mm})$. In our study, the mean joint line height elevation was not significantly different between the groups with $0.5 \mathrm{~mm}$ in the infected group and $2.1 \mathrm{~mm}$ in the non-infected group ( $\mathrm{p}=0.236$ ). $\mathrm{A} \geq 8 \mathrm{~mm}$ joint line height change was observed in 2 patients (9.5\%) in the infected group and in 1 patient $(6.7 \%)$ in the noninfected group and they obtained good results at the last followup examination. We believe this was because we used stemmed 
prostheses and metal augmentation to compensate for bone deficiency and soft tissue imbalance and took measures to restore the flexion and extension gap and the joint line height.

The limitations of this study include the retrospective study design, small number of patients, and short follow-up. Further, it is difficult to generalize our findings due to the small study population. Therefore, we believe the results should be confirmed in further studies with a large number of patients.

\section{Conclusions}

Revision TKA for non-infectious causes resulted in significantly better outcome than revision TKA for infection. However, revision TKA patients with infectious causes could obtain good results with the use of mobile antibiotic impregnated cement spacers for mobility maintenance during the healing period and proper implant selection for joint line height restoration.

\section{References}

1. Bae DK, Yoon KH, Kim HS, Song SJ, Yi JW, Kim YC. The results of revision total knee arthroplasty. J Korean Orthop Assoc. 2003;38:689-94.

2. Cameron HU, Hunter GA, Welsh RP, Bailey WH. Revision of total knee replacement. Can J Surg. 1981;24:418-20.

3. Kurtz S, Mowat F, Ong K, Chan N, Lau E, Halpern M. Prevalence of primary and revision total hip and knee arthroplasty in the United States from 1990 through 2002. J Bone Joint Surg Am. 2005;87:1487-97.

4. Goldberg VM, Figgie MP, Figgie HE 3rd, Sobel M. The results of revision total knee arthroplasty. Clin Orthop Relat Res. 1988;(226):86-92.

5. Jacofsky DJ, Della Valle CJ, Meneghini RM, Sporer SM, Cercek RM. Revision total knee arthroplasty: what the practicing orthopaedic surgeon needs to know. J Bone Joint Surg Am. 2010;92:1282-92.

6. Mulhall KJ, Ghomrawi HM, Engh GA, Clark CR, Lotke P, Saleh KJ. Radiographic prediction of intraoperative bone loss in knee arthroplasty revision. Clin Orthop Relat Res. 2006;446:51-8.

7. Ritter MA, Eizember LE, Fechtman RW, Keating EM, Faris PM. Revision total knee arthroplasty. A survival analysis. J Arthroplasty. 1991;6:351-6.

8. Insall JN, Dethmers DA. Revision of total knee arthroplasty. Clin Orthop Relat Res. 1982;(170):123-30.

9. Barrack RL. Early failure of modern cemented stems. J
Arthroplasty. 2000;15:1036-50.

10. Insall JN. Revision of total knee replacement. Instr Course Lect. 1986;35:290-6.

11. Windsor RE, Insall JN, Urs WK, Miller DV, Brause BD. Twostage reimplantation for the salvage of total knee arthroplasty complicated by infection. Further follow-up and refinement of indications. J Bone Joint Surg Am. 1990;72:272-8.

12. Barrack RL, Engh G, Rorabeck C, Sawhney J, Woolfrey M. Patient satisfaction and outcome after septic versus aseptic revision total knee arthroplasty. J Arthroplasty. 2000;15:9903.

13. Hwang SC, Cho SH, Jeong ST, Yune YP, Hwang IH. Clinical outcomes of infective and non-infective groups in revision total knee arthroplasty. J Korean Knee Soc. 2005;17:91-8.

14. Bose WJ, Gearen PF, Randall JC, Petty W. Long-term outcome of 42 knees with chronic infection after total knee arthroplasty. Clin Orthop Relat Res. 1995;(319):285-96.

15. Park SJ, Song EK, Seon JK, Yoon TR, Park GH. Comparison of static and mobile antibiotic-impregnated cement spacers for the treatment of infected total knee arthroplasty. Int Orthop. 2010;34:1181-6.

16. Patil N, Lee K, Huddleston JI, Harris AH, Goodman SB. Aseptic versus septic revision total knee arthroplasty: patient satisfaction, outcome and quality of life improvement. Knee. 2010;17:200-3.

17. Hanssen AD, Rand JA, Osmon DR. Treatment of the infected total knee arthroplasty with insertion of another prosthesis. The effect of antibiotic-impregnated bone cement. Clin Orthop Relat Res. 1994;(309):44-55.

18. Ewald FC. The Knee Society total knee arthroplasty roentgenographic evaluation and scoring system. Clin Orthop Relat Res. 1989;(248):9-12.

19. Goldstein WM, Kopplin M, Wall R, Berland K. Temporary articulating methylmethacrylate antibiotic spacer (TAMMAS). A new method of intraoperative manufacturing of a custom articulating spacer. J Bone Joint Surg Am. 2001;83 Suppl 2 Pt 2:92-7.

20. Hofmann AA, Goldberg T, Tanner AM, Kurtin SM. Treatment of infected total knee arthroplasty using an articulating spacer: 2- to 12-year experience. Clin Orthop Relat Res. 2005;(430):125-31.

21. Wang CJ, Hsieh MC, Huang TW, Wang JW, Chen HS, Liu CY. Clinical outcome and patient satisfaction in aseptic and septic revision total knee arthroplasty. Knee. 2004;11:45-9.

22. Bargren JH, Blaha JD, Freeman MA. Alignment in total knee arthroplasty. Correlated biomechanical and clinical 
observations. Clin Orthop Relat Res. 1983;(173):178-83.

23. Stulberg SD. Bone loss in revision total knee arthroplasty: graft options and adjuncts. J Arthroplasty. 2003;18:48-50.

24. Gofton WT, Tsigaras H, Butler RA, Patterson JJ, Barrack RL, Rorabeck CH. Revision total knee arthroplasty: fixation with modular stems. Clin Orthop Relat Res. 2002;(404):158-68.

25. Werle JR, Goodman SB, Imrie SN. Revision total knee arthroplasty using large distal femoral augments for severe metaphyseal bone deficiency: a preliminary study. Orthopedics. 2002;25:325-7.

26. Ducheyne P, Kagan A 2nd, Lacey JA. Failure of total knee arthroplasty due to loosening and deformation of the tibial component. J Bone Joint Surg Am. 1978;60:384-91.

27. Ewald FC, Jacobs MA, Miegel RE, Walker PS, Poss R, Sledge
CB. Kinematic total knee replacement. J Bone Joint Surg Am. 1984;66:1032-40.

28. Reckling FW, Asher MA, Dillon WL. A longitudinal study of the radiolucent line at the bone-cement interface following total joint-replacement procedures. J Bone Joint Surg Am. 1977;59:355-8.

29. Figgie HE 3rd, Goldberg VM, Heiple KG, Moller HS 3rd, Gordon NH. The influence of tibial-patellofemoral location on function of the knee in patients with the posterior stabilized condylar knee prosthesis. J Bone Joint Surg Am. 1986;68:1035-40.

30. Ryu J, Saito S, Yamamoto K, Sano S. Factors influencing the postoperative range of motion in total knee arthroplasty. Bull Hosp Jt Dis. 1993;53:35-40. 